CUADERNOS DE ESTUDIOS GALLEGOS, LXII Núm. 128 (enero-diciembre 2015), págs. 335-354

ISSN: $0210-847 \mathrm{X}$

DOI: 10.3989/ceg.2015.128.11

\title{
LOS OTROS NORUEGOS DE CANELIÑAS: LA CAMPAÑA BALLENERA DE 1929*
}

\author{
Felipe Valdés Hansen \\ Doctor en Historia
}

\footnotetext{
* Agradecimientos: A mi madre Annelie Hansen por la traducción de este documento del noruego al español en 2010. A mi padre Eduardo Valdés Parga. A Jesús Blanco por prestarme el libro de la CBE para su consulta y por su paciencia durante todo este tiempo. A Chesley W. Sanger y Anthony B. Dickinson por las noticias de la CBE al otro lado del Atlántico. A Hiurika y Jonás.
} 


\section{LOS OTROS NORUEGOS DE CANELIÑAS: LA CAMPAÑA BALLENERA DE 1929}

RESUMEN

El préstamo al autor de un documento inédito de la Compañía Ballenera Española, el libro de salarios de 1929, ha revelado nuevos datos sobre la actividad de los balleneros noruegos en Galicia en el siglo XX. Ello exige actualizar lo que sabíamos sobre su presencia en la factoría de Caneliñas, donde interrumpieron la actividad en 1927 ante la disminución de capturas (sobre todo en el estrecho de Gibraltar), la consiguiente caída de los beneficios y el aumento de los costos de explotación; además del interés de los directivos noruegos por trasladar el marco de operaciones al Antártico. El fracaso en 1928 de la Compañía Ballenera Internacional, que tenía previsto mantener operativa la factoría, marcó el destino a corto plazo de Caneliñas. Sin embargo, ahora sabemos que en 1929 la factoría fue reactivada breve y coyunturalmente al recalar allí la flota adquirida ese año por S. Foyn Bruun y A. von der Lippe, antes de unirse a su nueva factoría flotante (el Pontos) y partir rumbo al Antártico. Esta nueva fuente ha aportado valiosa información de la que carecíamos, como la organización del trabajo, la relación nominal de los trabajadores noruegos, sus salarios o las primas por captura y producción entre otros datos. Son «los otros balleneros» noruegos de los que nada sabíamos hasta el presente trabajo. Palabras Clave: Balleneros noruegos, ballenas, Galicia, Caneliñas.

\section{RESUMO}

OS OUTROS NORUEGUESES DE CANELIÑAS: A CAMPAÑA BALEEIRA DE 1929

O préstamo ao autor dun documento inédito da Compañía Ballenera Española, o libro de salarios de 1929, revelou novos datos sobre a actividade dos baleeiros noruegueses en Galicia no século XX. Polo tanto hai que actualizar o que sabiamos sobre a súa presenza na factoría de Caneliñas, onde interromperon a actividade en 1927 ante a diminución das capturas (sobre todo no estreito de Xibraltar), a conseguinte caída dos beneficios e o aumento dos custos de explotación; ademais do interese dos directivos noruegueses por trasladar o marco de operacións ao Antártico. O fracaso en 1928 da International Whaling Company, que tiña previsto manter operativa a factoría, marcou o destino a curto prazo de Caneliñas. Non obstante, agora sabemos que en 1929 a factoría foi reactivada breve e conxunturalmente ao recalar alí a frota adquirida ese ano por S. Foyn Bruun e A. von der Lippe, antes de unirse a súa nova factoría flotante (o Pontos) e partir rumbo ao Antártico. Esta nova fonte achegou valiosa información da que careciamos, como a organización do traballo, a relación nominal dos traballadores noruegueses, os seus salarios ou as primas por captura e produción entre outros datos. Son «os outros baleeiros» noruegueses dos que nada sabiamos ata o presente traballo.

Palabras Clave: Baleeiros noruegueses, baleas, Galicia, Caneliñas.

\section{THE OTHER NORWEGIANS OF CANELIÑAS: THE WHALING SEASON OF 1929}

\section{Abstract}

A previously unknown document from the Compañía Ballenera Española (Spanish Whaling Company), ceded to the author of this article, reveals new facts about the Norwegian whalers' activity in Galicia in the 20th. century. Therefore an updating of what we know about their activity at the Caneliñas factory becomes unavoidable. This activity was interrupted in the year 1927 due to the decreasing number of captures, especially in the Straits of Gibraltar, with a decrease in the Company's benefits and an increase in production costs, and the interest shown by the Norwegian management to relocate their activity in the Antarctic area. The 1928 failure on the part of the International Whaling Company to keep the factory open sealed the short term destiny of the Caneliñas factory. However, in 1929 the factory was briefly reopened again for a short period, when the newly acquired fleet that same year by S. Foyn Bruun and A. von der Lippe anchored there before joining their new floating factory, the Pontos, in their course to the Antarctic Ocean. This new documental source - the salaries register of CBE for the year 1929- provides a most valuable and previously unavailable information such as the work organization, a list of the company's payroll, specifying salaries and production and capture bonuses, and many other facts. These are «he other Norwegian whalers», of whom nothing was known up to this moment, as the present article is going to show.

KEY WORDS: Norwegian whalers, whales, Galicia, Caneliñas. 
Recibido/Received: 31/01/2015

Aceptado/Accepted: 10/08/2015

\section{El ocaso de la Compañía Ballenera Española}

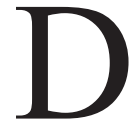
e las manos y dedos de Sedna, la diosa inuit protectora del mar, surgieron las ballenas, las focas y los peces. Que un barco ballenero llevase su nombre era una extraña paradoja a la que puso fin el propio mar, porque el Sedna se fue a pique en octubre de 1930. Cuando naufragó salía al encuentro de una factoría flotante aupada a lomos del Océano Antártico. Un año antes, todavía en Caneliñas, Olsen había cedido el puesto de arponero a Johan Theodorsen, hasta entonces al pie del cañón en el Solva. Ambos barcos y otros dos, el Symra y el Suiza, habían sido adquiridos por el principal propietario de la estación ballenera de Caneliñas, conjuntamente con otro socio, para abastecer de cetáceos su última adquisición: la factoría flotante Pontos. Los barcos se habían pasado las últimas campañas en las islas Sethland y en 1929 hicieron un alto en Galicia antes de poner rumbo al Antártico.

A pesar de su nombre la Compañía Ballenera Española, propietaria de la factoría de Caneliñas, era una sociedad de raíz noruega participada también por capital británico y español, tal como se analizó con detalle en la tesis doctoral del autor presentada y defendida en el año $2006^{1}$. Su primera fábrica, la de Getares en Algeciras (Cádiz), empezó a funcionar en 1921 y la de Caneliñas (A Coruña) en 1924. Sin embargo, el establecimiento de todas ellas coincidió en el tiempo con la caza a gran escala y expansión de las factorías flotantes itinerantes. Svend Foyn Bruun (1883-1956) y su socio Anton von der Lippe (1886-1960) se decantaron definitivamente por esta otra opción, al decaer las capturas al norte y sur de la Península Ibérica. Adquirieron dos buques, el Pontos y el Antarctic, constituyendo sendas compañías en torno a ellos: Hvalfangerselskapet Pontos A/S y Hvalfangerselskapet Antarctic A/S .

\footnotetext{
1 Felipe Valdés Hansen, La pesca de ballenas y cachalotes en Galicia desde el siglo XIII al XX. Estudio histórico y edición de documentos, Universidad de Santiago de Compostela, 2006.

2 Felipe Valdés Hansen, Los balleneros en Galicia (siglos XIII al XX), A Coruña, Fundación Pedro Barrié de la Maza, 2010 (Colección Galicia Histórica), pág. 255.
} 
La primera factoría costera de la compañía en paralizar su producción fue la de Getares en 1926, cuyos costos de producción la significaron negativamente dentro del grupo. Entre otras cosas, por ejemplo, se incrementó el consumo de carbón de los barcos al emplear más tiempo en el mar para localizar unos cetáceos cada vez más escasos; probablemente como consecuencia de la sobrepesca que precedió al cierre de la factoría ${ }^{3}$. De hecho, una de las campañas de Getares (la de 1923) estableció un hito productivo a nivel mundial entre las factorías del momento ${ }^{4}$. Un año antes del cierre, en 1925, los noruegos todavía pudieron salir del paso ante el accionariado achancando el mayor gasto en carbón a los temporales en la zona del estrecho de Gibraltar y a la huelga del carbón en Gran Bretaña ${ }^{5}$ Y sobre todo porque aquella campaña todavía fue muy provechosa con un beneficio bruto próximo a los cinco millones de pesetas, distribuyendo un dividendo extraordinario del 50\%, además del ordinario al 6\% de interés. Este buen resultado vino dado fundamentalmente por la campaña de Caneliñas que tiró del conjunto empresarial (483 cetáceos), dándose además la afortunada circunstancia de hallar un trozo de ámbar de más de cien kilos dentro de un cachalote. Su venta reportó medio millón de pesetas a la empresa ${ }^{6}$, es decir, casi tanto como para enjugar la inversión realizada en material de caza y herramientas aquel año.

La realidad de Getares obligó a la gerencia noruega de la CBE a no ignorar el problema por más tiempo e intervenir decididamente. Así lo hicieron y de tal modo que se "llevaron" la fábrica al otro lado del Atlántico. En octubre de 1926 se constituyó en Canadá la British Norwegian Whaling Company reproduciendo el modelo de la CBE, es decir, involucrando en el negocio a pequeños accionistas locales para obtener respaldo financiero y, sobre todo, político. Seguidamente trasladaron a su nueva factoría instalada en la isla de Grady (Terranova-Labrador) la maquinaria de Getares y tres barcos: el Pepita Maura, el Caneliñas y el Condesa del Moral de Caltrava ${ }^{7}$. A través de esta aportación aquella otra empresa pasó a estar mayoritariamente participada por la Compañía Ballenera Española.

Sin embargo, la operación fue un fracaso que probablemente aceleró el definitivo desinterés de Bruun y Lippe por las factorías terrestres, incluyendo la de Caneliñas, la más importante del grupo. Prueba de esto último es que la de Caneliñas estaba valorada en 71.600 libras, el doble que la de Labrador (36.500

\footnotetext{
3 F. Valdés Hansen, Los balleneros en ..., pág. 252.

4 F. Valdés Hansen, Los balleneros en ..., pág. 250.

5 Compañía Ballenera Española (ed.), Memoria correspondiente al ejercicio del $1^{\circ}$ de enero al 31 de diciembre de 1925, Compañía Ballenera Española, Madrid, Pérez y Coca, 1926.

6 Alejandro Lastres Carrera, "En la factoría de Caneliñas: Medio millón de pesetas en ámbar", La Voz de Galicia, 04/02/1925, pág. 1.

7 Anthony B. Dickinson y Chesley W. SANGer, Twentieth-century shore-station whaling in Newfoundland and Labrador, Montreal, McGill-Queen's University Press, 2005, pág. 116.
} 
Tabla 1. Balance de la CBE en 1925

\begin{tabular}{|l|c|}
\hline Ventas y gastos & Pesetas \\
\hline Aceites & $5.581 .135,85$ \\
\hline Guano & $1.075 .655,02$ \\
\hline Barbas & $23.172,09$ \\
\hline Ámbar gris & $495.907,59$ \\
\hline Existencias sin vender & $1.561 .960,00$ \\
\hline Total ventas y existencias & $8.737 .830,55$ \\
\hline Costos de producción* & $-3.954 .347,20$ \\
\hline Beneficio bruto & $4.783 .483,35$ \\
\hline Gastos empresariales ** & $-2.534 .282,95$ \\
\hline Beneficio neto & $2.249 .200,40$ \\
\hline Distribución de beneficios & $-2.092 .802,09$ \\
\hline Remanente para 1926 & $200.352,77$ \\
\hline
\end{tabular}

* Barriles, sacos, carbón, material de caza y herramientas, jornales, etc.

** Gastos generales, de ventas y viajes, reparaciones, seguros, derechos de puerto, etc. Fuente: Memoria correspondiente al ejercicio del $1^{\circ}$ de enero al 31 de diciembre de 1925 , Compañia Ballenera Española, Madrid, 1926.

libras), mientras que la desmantelada factoría de Getares sólo se estimaba en 4.500 libras $^{8}$. El intento por reaprovechar la maquinaria de Getares concluyó ahí $\mathrm{y}$, todavía hoy, una parte de ésta yace oxidada sobre la turbera de aquella isla. El rendimiento de Grady estuvo siempre muy por debajo de las mejores campañas peninsulares: 75 cetáceos en 1927 y 121 en 1928. En este contexto cualquier contratiempo grave era un problema casi definitivo, al contrario de lo que supuso, por ejemplo, el embarrancamiento del vapor de transporte Blus en Caneliñas en 1925. Fue el caso de la pérdida del Pepita Maura en 1928, sólo unas semanas después de haber sufrido un accidente en alta mar que lo dejó a la deriva durante horas y en el dique seco parte de la campaña. Aquel primer "aviso" se lo dio un cachalote que, de un golpe, destrozó una sección de la popa, el timón y la hélice:

8 Archivo del autor, folleto de la Compañía Ballenera Internacional (1928). 


\section{Ballenero embarrancado en Labrador \\ El barco fue dañado por un cachalote}

El ballenero Pepita Maura embarrancó en Watering Cove, cerca de Grady, durante la tormenta de la pasada noche y se supone totalmente perdido. El Pepita Maura es propiedad de la British Norwegian Whaling Company que opera en Grady. Job Bros son los agentes locales de la compañía. A finales de agosto el Pepita Maura arponeó un cachalote a 43 millas al este de la factoría. La ballena cargó contra el barco arrancando el timón, una pala de la hélice, la estructura de popa y una parte del fondo. El golpe fue tan grande que los que estaban a bordo en el pequeño barco pensaron que iba a ser destrozado. El Earl of Devon se dirigía a Grady para remolcar el barco hasta ahi'.

Las factorías de la $\mathrm{CBE}$ cayeron como piezas de dominó una detrás de otra: Getares (1926), Caneliñas (1927) y Grady (1928). En la de Caneliñas la actividad se interrumpió abruptamente en agosto de 1927 . Y es que, a pesar de haber iniciado tempranamente aquella campaña, al llegar al ecuador de la misma tan sólo habían completado el 50\% de las capturas realizadas un año antes por aquellas mismas fechas. La falta de rorcuales llevó incluso a los arponeros a dirigir el punto de mira sobre los "olvidados" cachalotes (menos atractivos comercialmente), cazando más ejemplares de esta espacie en el último mes, el de julio de 1927 (41), que en todas las campañas anteriores (Tabla 4).

Al año siguiente, mientras confiaban en la recuperación del caladero peninsular con las dos factorías inactivas, el proyecto fallido de la Compañía Ballenera Internacional marcó el destino de Caneliñas. La última anotación de la compañía en el libro del registro mercantil fue realizada en el verano de 1928. En la misma se otorgaba un poder al secretario Manuel Nogueira en nombre de un consejo de administración controlado por los noruegos y con la vista puesta ya en otras latitudes ${ }^{10}$. La sobrevenida campaña de 1929 es relativamente corta, coyuntural y

\footnotetext{
9 Texto original en inglés: Ship was damaged by a sperm whale: The whaling ship Pepeta Maura (sic) drove ashore at Watering Cove near Grady during a storm last night and is supposed to be a total loss. The Pepeta Maura (sic) is owned by the British Norwegian Whaling Co., who are operating Grady. Messrs. Job Bros are the local agents of the Company. During the latter part of August the Pepeta Maura (sic) harpooned a sperm whale about 43 miles east of the station. The whale charged the ship, tore away her rudder, a propellor blade, the stern frame and part of the shoe. The shock was so great that those on board the little ship thought she would be demolished. The Earl of Devon was proceeding to Grady to tow the ship on here. Anónimo, "Whaler ashore in Labrador", Evening Telegram, 01/09/1928. A. B. Dickinson y C. W. SANGer, Twentieth-century..., pág. 116.

${ }^{10}$ Registro Mercantil de Madrid, tomo 77, hoja 3.046 duplicado, fols. 132-133.
} 
poco importante considerando el número de capturas (15 cetáceos) y la producción (Tablas 3 y 4). Ni siquiera el omnipresente gerente Herlofson -que en 1927 había sido trasladado a la factoría de Grady- estaba al frente de Caneliñas.

Tabla 2. Flota ballenera en Caneliñas en 1929

\begin{tabular}{|l|l|l|l|l|}
\hline Nombre & Construcción & TRB & Eslora / manga / puntal & Final o baja \\
\hline Sedna & Middlesbrough (1912) & 192 & $32,4 / 6,5 / 3,8$ & Naufragio (1930) \\
\hline Symra & Middlesbrough (1912) & 192 & $32,4 / 6,5 / 3,8$ & No consta (ca. 1941)* \\
\hline Suiza & Porsgrund (1913) & 167 & $31,8 / 6,1 / 3,5$ & Desguazado (1936) \\
\hline Solva & Oslo (1913) & 137 & $30,2 / 5,9 / 3,5$ & Desguazado (1936) \\
\hline
\end{tabular}

*Vendido a empresas japonesas, hundido o destruido durante la II Guerra Mundial. Fuente: Lardex Group (Noruega).

Tabla 3. Capturas procesadas en Caneliñas (13 abril-9 julio 1929)

\begin{tabular}{|l|c|c|c|}
\hline Barco & R. común & Cachalote & Total \\
\hline Sedna & 3 & 3 & 6 \\
\hline Symra & 2 & 2 & 4 \\
\hline Suiza & 2 & 1 & 3 \\
\hline Solva & 1 & 1 & 2 \\
\hline Total & 8 & 7 & 15 \\
\hline
\end{tabular}

Fuente: Libro de salarios de la CBE, año 1929.

Tabla 4. Producción de Caneliñas (1924-29)

\begin{tabular}{|l|c|c|c|c|c|c|}
\hline & 1924 & 1925 & 1926 & 1927 & 1928 & 1929 \\
\hline Rorcuales & 7 & 453 & 622 & 198 & 0 & 8 \\
\hline Cachalotes & 6 & 30 & 3 & 45 & 0 & 7 \\
\hline Barriles aceite & 438 & 11.170 & 18.338 & 4.593 & 0 & 604 \\
\hline Sacos guano & - & 17.781 & 26.589 & 6.532 & 0 & 420 \\
\hline
\end{tabular}

Fuentes: F. VALdés Hansen, Los balleneros en ..., pág. 310. Libro de salarios de la CBE, año 1929. 


\section{La Compañía Ballenera InTERnaCional}

Entre 1927 y 1928 Bruun y Lippe fraguaron en Tønsberg el inminente final de la Compañía Ballenera Española. Inicialmente, sopesaron hacerlo a través de un ambicioso proyecto que no llegó concretarse: la International Whaling Company o Compañía Ballenera Internacional, concebida para absorber a la CBE y trasladar el marco de operaciones a los caladeros más productivos. En la misma participaría nada menos que Anders Jahre, magnate noruego de la industria ballenera internacional al frente de varias compañías y de otras tantas factorías flotantes ${ }^{11}$.

La nueva compañía debería adquirir la totalidad del capital de la CBE (1.560 acciones de 1.000 pta. cada una) que, a su vez, poseía el 98\% de la British Norwegian Whaling Co. Ltd. (3.000 acciones de $100 \$$ cada una) $)^{12}$. De este modo, además de las fábricas, los siete barcos balleneros de Caneliñas y Grady pasarían a la nueva compañía, proyectando además la compra de otros cinco. Por otro lado, planteaban la adquisición de dos barcos que transformarían en factorías flotantes para operar en mar abierto. La idea inicial era mantener operativas las fábricas de Galicia y Canadá, mientras la de Algeciras continuaría en la reserva. No obstante, el grueso de la producción y de los beneficios tendrían que llegar de la mano de las dos factorías flotantes. Los planes en torno a la Compañía Ballenera Internacional son la plasmación del giro dado por Bruun y Lippe, tras la experiencia de los últimos años en Galicia y en el estrecho de Gibraltar:

Los más importantes y aprovechables bancos de ballena del mundo se encuentran en las aguas del Antártico y Sub-Antártico, cerca de los bancos de hielo que circundan las regiones polares y en la vasta extensión de océano al sur de África, América y Australia; inmensas extensiones de agua abundantes de ballenas de varias especies, las que hasta ahora sólo han sido explotadas comercialmente en la proximidad de Georgia del Sur y Shetland del Sur, en América meridional.

Hasta los dos últimos años la caza de ballenas fue dirigida principalmente desde estaciones o factorías terrestres, de las que los barcos cazadores salían a los bancos de pesca, hacian sus capturas $y$ volvían con ellas a remolque a las factorías o bases terrestres en las que se extraía el aceite de ballena y otros productos.

Las ballenas siguen siempre a su alimento y aunque en una temporada pueda hacerse una buena caza en la vecindad de la

\footnotetext{
${ }^{11}$ Archivo del autor, folleto de la Compañía Ballenera Internacional (1928).

12 Íbidem.
} 
factoría terrestre, en la siguiente temporada puede haber menos alimento en aquellas aguas y, consecuentemente, menor número de ballenas. Por esta causa se apreciará rápidamente que el mayor éxito se obtiene si la factoría puede seguir a las ballenas de sitio en sitio a medida que emigran ${ }^{13}$.

La participación de Jahre en este sentido era fundamental. Los telegramas de sus factorías flotantes, que él trasladaba a sus socios de Tønsberg, auguraban exitosas campañas para la nueva empresa ${ }^{14}$. La compañía se constituiría y cotizaría en Londres, siguiendo el éxito de otras muchas empresas balleneras anglo-noruegas que hicieron posible la expansión de los noruegos por casi todos los mares. Intentando atraer nuevos accionistas Bruun y Lippe blandieron los altos beneficios distribuidos por la $\mathrm{CBE}$, mientras auguraban otro tanto o más para el nuevo proyecto reforzado con dos factorías flotantes ${ }^{15}$. Los principales accionistas entrarían en el consejo de administración en Londres y, a semejanza de la CBE, los tres socios noruegos se garantizaban el control del mismo al reservarse los cargos de directores gerentes y consejeros en Noruega. Descartando la reactivación de Getares, aseguraban que podrían llegar a distribuir beneficios de 16.000 libras por cada una de las dos factorías terrestres, la de Galicia y Labrador, y otras 220.000 por las dos factorías flotantes. En total 252.000 libras, es decir, el 36\% del capital de la nueva compañía fijado en 700.000 libras $^{16}$.

Sin embargo, al igual que otros proyectos coetáneos que también acudieron a Londres, la suscripción de las setecientas mil acciones fue un fracaso que terminó con la Compañía Ballenera Internacional antes de tiempo. Fue precisamente Anders Jahre quien sugirió entonces la vuelta a casa y puesta en marcha allí de empresas netamente noruegas, ante el cambio de coyuntura en Londres ${ }^{17}$. Los tres socios comenzaron desde ese mismo momento a sacar adelante lo esencial de la Compañía Ballenera Internacional (las factorías flotantes), a través de sociedades constituidas y financiadas en Noruega como Pelagos, Antarctic y Pontos.

\footnotetext{
${ }_{13}$ Archivo del autor, folleto de la Compañía Ballenera Internacional (1928).

${ }^{14}$ Partes telegráficos recibidos del vapor Lancing, de la compañia Globus, informan de haber obtenido - por lo menos cuatro meses antes del tiempo previsto-un cargamento completo equivalente a 47.200 barriles, obteniendo un beneficio neto de aproximadamente 130.000 libras en el viaje; mientras el NT Nielsen Alonso, de la compañia Polaris, informa que ahora está obteniendo más de 1.500 barriles al día, un record en la historia de las balleneras. Durante siete semanas, desde el 22 de enero, este buque ha obtenido no menos de 43.000 barriles de aceite. Archivo del autor, folleto de la Compañía Ballenera Internacional (1928).

${ }^{15}$ Distribución de beneficios de la CBE: 24\% (1923), 46\% (1924), 56\% (1925) y 56\% (1926).

${ }^{16}$ Archivo del autor, folleto de la Compañía Ballenera Internacional (1928).

17 Johan Nicolay Tonnessen y Arne Odd JoHnsen, The history of modern whaling, Berkeley y Los Ángeles, University of California Press, 1982, pág. 375.
} 
En 1928 adquirieron un carguero de construcción inglesa (1906) que transformaron en una factoría flotante en los astilleros Akers de Oslo, dándole el mismo nombre que la compañía constituida en paralelo: Antarctic. Al servicio de este barco asignaron los balleneros supervivientes de la CBE (Galicia, Caneliñas, Leslie, William Wilson y Morote) ${ }^{18}$. El caso del Pontos (construido en Belfast en 1890 ) es diferente, pues ya había sido reconvertido en factoría flotante cuando lo adquirieron Bruun y Lippe en 1928; teniendo tan sólo que ponerlo a punto en Noruega al volver de su última expedición ${ }^{19}$. Llegó a Sandefjord en junio de 1929, mientras los cuatro balleneros adquiridos para prestarle apoyo (el Solva, Suiza, Symra y Sedna) cazaban y aguardaban instrucciones en Caneliñas. En julio, al completar la descarga, fue enviado al astillero hasta finales de agosto ${ }^{20}$. Por aquel entonces los balleneros habían dejado de cazar ya para Caneliñas, uniéndose después al Pontos para realizar la primera campaña antártica en el verano austral de 1929/30. Después la flota se redujo a tres balleneros, tras la baja por naufragio del Sedna. Antes de eso, en Galicia, cazaron quince cetáceos entre los meses de abril y julio de 1929. Sus tripulantes lo hicieron al servicio de la Compañía Ballenera Española, al igual que los trabajadores de la factoría de Caneliñas. De todos ellos, con nombres y apellidos, tenemos constancia documentada.

\section{El LiBRo DE SALARIOS DE 1929}

La de 1929 fue poco importante en lo cuantitativo (capturas y producción), pero en lo cualitativo es - hasta que no aparezcan nuevas fuentes- la campaña noruega mejor documentada que, además, proyecta una luz desconocida sobre todas las demás y la etapa ballenera noruega en su conjunto. La fuente que ha permanecido inédita durante más de ochenta años fue cedida al autor en el 2010 por el ballenero retirado Jesús Blanco, a raíz de la publicación de la tesis doctoral del autor ese mismo año. Jesús, vecino de Gures, la localidad más próxima a la factoría de Caneliñas, fue uno de los últimos balleneros de IBSA (Industria Ballenera S.A.) hasta 1985. Su padre, a su vez, fue uno de los trabajadores más veteranos de la segunda etapa de la factoría de Caneliñas (1951-1985), construida sobre las ruinas de la primera de origen noruego. Probablemente el libro quedó olvidado en alguno de aquellos edificios y pasó a manos de la familia en torno a 1934, teniendo en cuenta la primera de las anotaciones realizadas con posterioridad. También cabe la posibilidad que hubiese quedado en manos del secretario de la compañía Johan Nannestad (1901-1963), el único de los noruegos que decidió no volver a

\footnotetext{
18 F. VAldés Hansen, Los balleneros en ..., págs. 255, 287.

19 Skipshistorie [en línea], disponible en <http://www.skipshistorie.net> [Consulta: 04/05/2014].

${ }^{20}$ Skipshistorie [en línea], disponible en <http://www.skipshistorie.net $>$ [Consulta: 04/05/2014]. 
su país y que incluso trabajó después como guardián y mandadero en la factoría que estableció IBSA en Caneliñas. De hecho, es probable que los registros sean obra del puño y letra del propio Nannestad; en total cincuenta y cinco folios con información de otros tantos trabajadores, sin contar el índice inicial.

El libro está escrito en noruego y es un registro salarial del personal noruego embarcado y de factoría, incluyendo las primas como complemento del salario base. Gracias a esto último conocemos el número de capturas y la producción, porque las primas se establecían por cetáceo capturado en el caso de las tripulaciones (Tabla 5), mientras que las del personal de tierra venían determinadas por la producción de barriles de aceite y sacos de guano (Tabla 7). La cuantía de los incentivos permite intuir que representaban la parte más importante de la remuneración mensual de todos los trabajadores, aunque, obviamente, no es el caso de esta campaña con un bagaje de capturas tan escaso. Las primas más cuantiosas son las del arponero, sobre el que recaía en última instancia la mayor responsabilidad. Por ello, además de la prima por cetáceo, el arponero tenía otra adicional al final de la campaña dependiendo del número total de piezas (Tabla 6).

Tabla 5. Salarios mensuales y primas (kr.) de las tripulaciones (1929)

\begin{tabular}{|l|c|c|c|c|c|}
\hline \multirow{2}{*}{ Tripulante } & \multirow{2}{*}{ Salario mensual } & \multicolumn{4}{|c|}{ Primas } \\
\cline { 3 - 6 } & & $\begin{array}{c}\text { Rorcual } \\
\text { azul }\end{array}$ & $\begin{array}{c}\text { Rorcual } \\
\text { común }\end{array}$ & $\begin{array}{c}\text { Cachalote } \\
\text { grande* }\end{array}$ & $\begin{array}{c}\text { Cachalote } \\
\text { pequeño }\end{array}$ \\
\hline Arponero & 300 & 100 & 50 & 50 & 25 \\
\hline Primer maquinista & 350 & 18 & 13 & 12 & 6 \\
\hline Timonel & 220 & 12 & 8 & 8 & 4 \\
\hline Segundo maquinista & 200 & 11 & 7 & 7 & 3 \\
\hline Marinero & 150 & 11 & 7 & 7 & 3 \\
\hline Fogonero & 145 & 11 & 7 & 7 & 3 \\
\hline Cocinero-marmitón & 200 & 11 & 7 & 7 & 3 \\
\hline
\end{tabular}


Tabla 6. Primas del arponero al final de campaña (kr.)

\begin{tabular}{|l|c|c|}
\hline Total de cetáceos & Por cetáceo & Por cachalote pequeño \\
\hline $1-75$ & 50 & 25 \\
\hline $76-100$ & 80 & 40 \\
\hline 101 o más & 100 & 50 \\
\hline
\end{tabular}

Fuente: Libro de salarios de la CBE, año 1929.

Tabla 7. Salarios mensuales y primas del personal de factoría (1929)

\begin{tabular}{|l|c|c|c|}
\hline Cargo & Salario mensual (kr) & Prima por barril (øre) & Prima por saco (øre) \\
\hline Capataz & 400 & 15 & 5 \\
\hline Maquinista & 350 & 15 & 5 \\
\hline Mecánico & 300 & 15 & 5 \\
\hline Secretario & 300 & 5 & 4 \\
\hline Marmitón / ayudante & 275 & 6 & 3 \\
\hline Herrero & 250 & 6 & 3 \\
\hline Capataz de la carne & 225 & 7 & $3 / 2$ \\
\hline Cocinero & $225 / 160$ & $8 / 5$ & 2 \\
\hline Secretario & $200 / 160$ & 5 & 2 \\
\hline Carpintero & 190 & 5 & 8 \\
\hline Encargado secadora & 175 & 2 & $1(1929)$ \\
\hline Mozo & $40(1927-28)$ & $1(1927)$ & \\
\hline & $75(1928-29)$ & $2(1929)$ & \\
\hline
\end{tabular}

Fuente: Libro de salarios de la CBE, año 1929.

La relación de tripulantes permite conocer que en los barcos navegaban cuatro marineros en cubierta, incluyendo el timonel, otros cuatro en máquinas, el cocinero y el arponero. Todos ellos noruegos y a sueldo de la Compañía Ba- 
llenera Española. En el caso de los balleneros gallegos de la segunda mitad del siglo XX, en cambio, no existía el puesto de timonel como tal. Los marineros de cubierta se alternaban al timón en turnos de una hora, por lo que no había a bordo un tripulante especializado en la aproximación al cetáceo justo antes de arponearlo; algo importante que, sin embargo, sí parece tenían en cuenta los noruegos. Considerando esa experiencia de los timoneles, además de la necesaria confianza o sintonía que cabría suponerles con los arponeros, no es de extrañar que el timón fuese un puesto idóneo para pasar después al cañón. De hecho, uno de los timoneles que estuvo en Caneliñas en 1929 -Harry Lauritsen- se estrenó como arponero a bordo del Solva en plena campaña (Tabla 8).

No tenemos noticia de gallegos a bordo de estos cuatro barcos. El personal español a bordo y al mando de los balleneros fue uno de los requisitos de la concesión otorgada a la CBE en 1921 (R.O. de 9 de julio de 1921) ${ }^{21}$. La administración permitió que la mitad de los marineros de cubierta fuesen extranjeros, teniendo en cuenta la inexperiencia en torno a la renacida industria ballenera moderna. Sin embargo, la realidad fue bien distinta y, al igual que en tierra, los noruegos se reservaron los puestos cualificados y mejor remunerados. De ello tenemos incluso esporádica noticia por la crónica del escritor Wenceslao Fernández Flórez, el cual estuvo a bordo del William Wilson en Galicia ${ }^{22}$. En este barco la mayor parte de los tripulantes eran noruegos, incluyendo el capitán, y del testimonio del escritor se deduce que los gallegos eran enrolados tan sólo como marineros de segunda. Por lo tanto cabe suponer un incumplimiento aun mayor en este sentido en el caso de la flota de 1929, considerando lo coyuntural de su actividad. Sobre todo sabiendo que cada ballenero estaba tripulado por diez noruegos (Tabla 8), mismo número o próximo al de marineros por barco de la $\mathrm{CBE}$ en las campañas anteriores (de diez a once). Los gallegos probablemente también constituían el bloque de la tripulación no noruega en los barcos de Getares, teniendo en cuenta el testimonio del naturalista Ángel Cabrera que estuvo a bordo en uno de ellos ${ }^{23}$.

\footnotetext{
${ }^{21}$ Siendo los buques de procedencia extranjera sólo podrán dedicarse a la pesca de altura y gran altura, recayendo el mando de los mismos y la jefatura de las máquinas, así como la provisión de los cargos náuticos y mecánicos, en personal precisamente español y con arreglo al cuadro indicador aprobado por Real orden de 4 de Febrero de 1915. En cuanto el personal marinero de cubierta y al técnico necesario, para la pesca por procedimiento desconocido hasta ahora en España, se le autoriza para que la mitad de los marineros de cubierta y el personal técnico que manifieste serle indispensable y tiene ya contratado pueda ser extranjero. Gaceta de Madrid, Madrid, núm. 201 (20/07/1921), pág. 361.

22 Wenceslao Fernández Flórez, La conquista del horizonte, Zaragoza, Librería General, 1942, pág. 27.

${ }^{23}$ La dotación de cada barco, formada por noruegos y españoles, principalmente gallegos, se compone de once hombres, incluyendo el capitán que es a la vez el artillero. Ángel CABRERA, "Los grandes cetáceos del estrecho de Gibraltar, su pesca y explotación”, Trabajos del Museo Nacional de Ciencias Naturales, 52 (1925), pág. 12.
} 
En la factoría los noruegos también copaban los puestos de mayor cualificación, responsabilidad o confianza: la gerencia, la secretaría, los capataces, los jefes de sección e incluso los ayudantes y el cocinero ${ }^{24}$. La mano de obra local no incluida en el registro de salarios, probablemente por estar contratada a destajo, se destinaba en consecuencia a los trabajos menos cualificados y peor remunerados en las diferentes secciones: peones de plataforma, de almacén, calderas, etc. Las horas de trabajo, en cambio, sí eran elevadas. La sorprendente huelga organizada en Caneliñas en 1925, exigiendo un horario de ocho horas y el aumento del jornal, nos da una idea de la dureza de las condiciones en las que desempeñaron su trabajo $^{25}$. La historia se repetirá y los trabajadores de la segunda época, la de IBSA (1951-85), también coincidirán en destacar la dureza del trabajo en los primeros años, solapándose las jornadas diurnas y nocturnas en la ballenera sin apenas descanso ${ }^{26}$. Explotación en tierra y en el mar; de hombres y ballenas.

Por lo tanto el registro de salarios de la $\mathrm{CBE}$ es una fuente doblemente importante. En primer lugar atestigua una campaña de la que no teníamos noticia, la de 1929, ignorada en todos los trabajos sobre la actividad ballenera del siglo XX en Galicia; desde el capítulo monográfico -y casi coetáneo- de Ángel Bernárdez hasta el reciente libro de Aguilar publicado en 2013, incluyendo las obras de Patiño y Seage (1989), Quiroga (2002) o la citada tesis doctoral del autor del presente artículo ${ }^{27}$. La escasa importancia de la campaña, su eventualidad y las particulares circunstancias que la rodearon están detrás de ese silencio u olvido que se constata ya entonces. Porque de estos noruegos, en cambio, no quedó rastro en la prensa local de la época que, sin embargo, sí dedicó frecuentes crónicas a la ballenera de Caneliñas en los años anteriores. El cambio de rumbo dado por los noruegos, cuyos intereses pasaban ya por el Antártico, debió influir en el poco eco dado. En segundo lugar, y paradójicamente teniendo en cuenta lo ya dicho sobre la campaña del 29, el libro aporta una información muy valiosa e inédita sobre la compañía extrapolable a todas las temporadas precedentes a grandes rasgos (organización y división del trabajo, retribuciones, primas, tripulaciones, etc.). La poca importancia de la campaña probablemente es también la razón por la que el libro de salarios tuvo un destino diferente al resto de la documentación

\footnotetext{
${ }^{24}$ Felipe ValdÉs Hansen, “A factoría baleeira de Balea (Cangas)”, Eubalanea, 14 (2014), pág. 49.

${ }^{25}$ F. Valdés Hansen, Los balleneros en ..., pág. 330.

${ }^{26}$ F. Valdés Hansen, Los balleneros en ..., págs. 381-384

27 Ángel Bernárdez, "La pesca en Galicia", en F. Carreras Candi (ed.), Geografía General del Reino de Galicia, vol. 1, Barcelona, Ed. Alberto Martín, 1936, págs. 517-553. Xosé Penas Patiño y Antonio Piñeiro Seage, Cetáceos, focas e tartarugas mariñas das costas ibéricas, Santiago de Compostela, Dirección Xeral de Formación e Promoción Social Pesqueira, 1989. Héctor QuirogA, La caza de ballenas en aguas ibéricas, A Coruña, Diputación de A Coruña, 2002. Àlex AguilaR, Chimán, Barcelona, Universidad de Barcelona, 2013.
} 
empresarial de la CBE, la cual los noruegos sí tuvieron la precaución de llevársela consigo o destruirían, una vez perdida su utilidad inmediata.

Tabla 8. Tripulaciones (1929)

\begin{tabular}{|c|c|c|c|c|}
\hline Tripulante & Symra & Sedna & Solva & Suiza \\
\hline Arponero & Harald Hansen & $\begin{array}{l}\text { Karl M. Olsen* } \\
\text { J. Theodorsen }\end{array}$ & Johan Theodorsen ${ }^{* *}$ & - \\
\hline Timonel & Lars Andersen & Nils Olanssen & Harry Lauritsen & $\begin{array}{l}\text { Andreas Henry } \\
\text { Johannesen }\end{array}$ \\
\hline Marinero & $\begin{array}{l}\text { Anders Kristian Andersen } \\
\text { Andersen }\end{array}$ & Mikal Arvesen & $\begin{array}{l}\text { Johannes A. } \\
\text { Johnsen }\end{array}$ & Nils B. Pedersen \\
\hline Marinero & $\begin{array}{l}\text { Ansgar Mathisen } \\
\text { Martinsen }\end{array}$ & Nils Herman & Arut 0 . Magnussen & $\begin{array}{l}\text { Sigurd Hjalmar } \\
\text { Suberg }\end{array}$ \\
\hline Marinero & Karl Johan Larsen & David Ellingsen & Ingvald M. Larsen & $\begin{array}{l}\text { Thor Reidar } \\
\text { Antonsen }\end{array}$ \\
\hline $1^{\text {er }}$ maquinista & Asbjørn Hansen & Srun Ellefsen & Ernst K. Eriksen & Olaf Steen Ellefsen \\
\hline $2^{\circ}$ maquinista & Oskar Fredrik Johansen & Karl Ivar Karlsson & $\begin{array}{l}\text { Trygve Marinius } \\
\text { Hansen }\end{array}$ & Emil Klausen \\
\hline Fogonero & Arthur W. Eilerben & Erling Lie & F.K. Johannesen & Helge P. Helgesen \\
\hline Fogonero & Asbjørn K. Bjørgum & Magnus K. Eidet & $\begin{array}{l}\text { Henry Hildemar } \\
\text { Hansen }\end{array}$ & $\begin{array}{l}\text { Buge Johansen } \\
\text { /Einar Johansen }\end{array}$ \\
\hline Cocinero & Severin A. Hansen & Fredrik Conradi Arild & $\begin{array}{l}\text { Hans Ingvald Hansen } \\
\text { Hansen }\end{array}$ & Anders Knudsen \\
\hline
\end{tabular}

* Arponero hasta el 29/06/1929.

** J. Theodorsen pasa del Solva al Sedna el 13/06/1929, para remplazar a Olsen. Harry Lauritsen le sustituye como arponero del Solva, pasando J. A. Johnsen al timón.

Fuente: Libro de salarios de la CBE, año 1929. 
Tabla 9. Trabajadores noruegos de Caneliñas (1929)

\begin{tabular}{|l|l|}
\hline Nombre & Cargo \\
\hline C.B. Christiansen & Gerente \\
\hline Johan Nannestad & Secretario \\
\hline Einar Knox Andersen* & Ayudante / mozo \\
\hline Thormand Vik & Secretario \\
\hline Fredrik S. Nielsen & Marmitón \\
\hline Olav Dahl & Ayudante / mozo \\
\hline Hans Hesley & Encargado de la secadora \\
\hline Harald Nielsen & Herrerro \\
\hline Bjarne Christophersen & Mecánico \\
\hline Ole Staabrid & Maquinista \\
\hline Karl Olafsen & Cocinero \\
\hline Aksel Brekke & Capataz de la carne \\
\hline Hans A. Hansen & Capataz \\
\hline Ostein Spue & Carpintero \\
\hline Kristian Nordendahl & Cocinero \\
\hline
\end{tabular}

* Por las fechas de su asignación salarial se deduce que este trabajador fue el único que permaneció en la factoría desde el verano de 1927.

Fuente: Libro de salarios de la CBE, año 1929. 


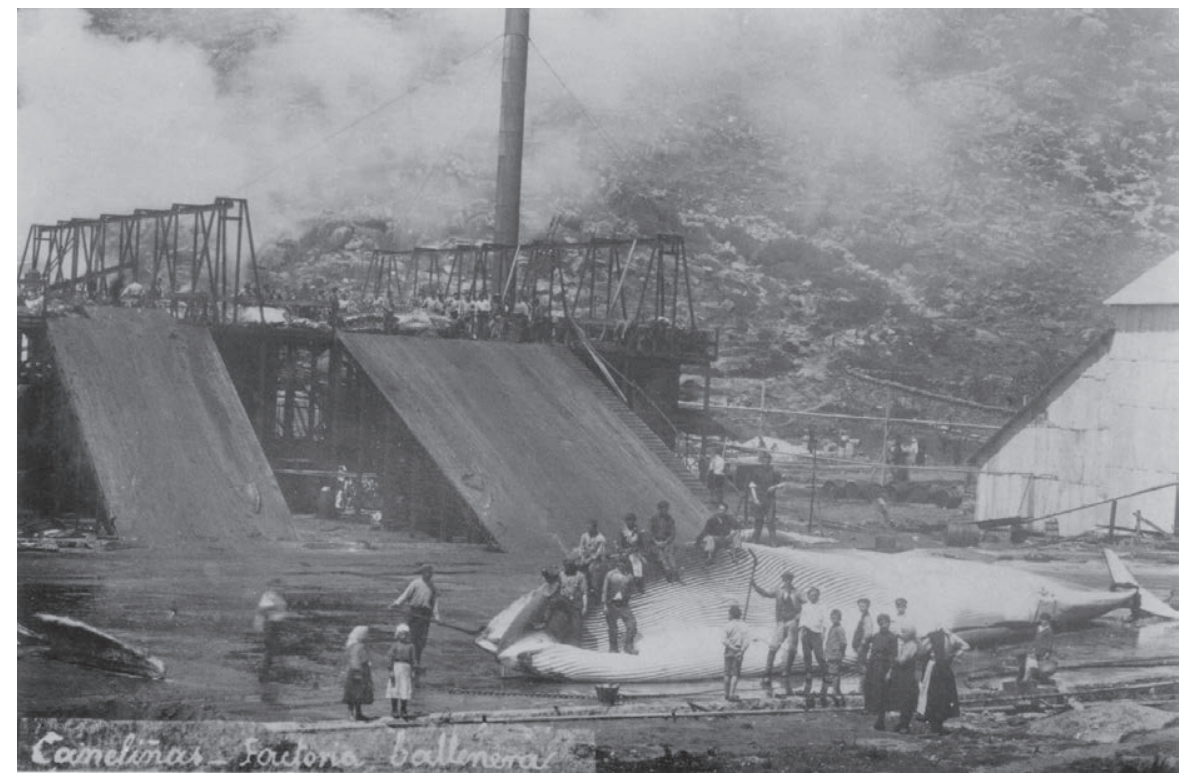

Fig. 1. Trabajadores y trabajadoras en la factoría de Caneliñas (Museo de Pontevedra).

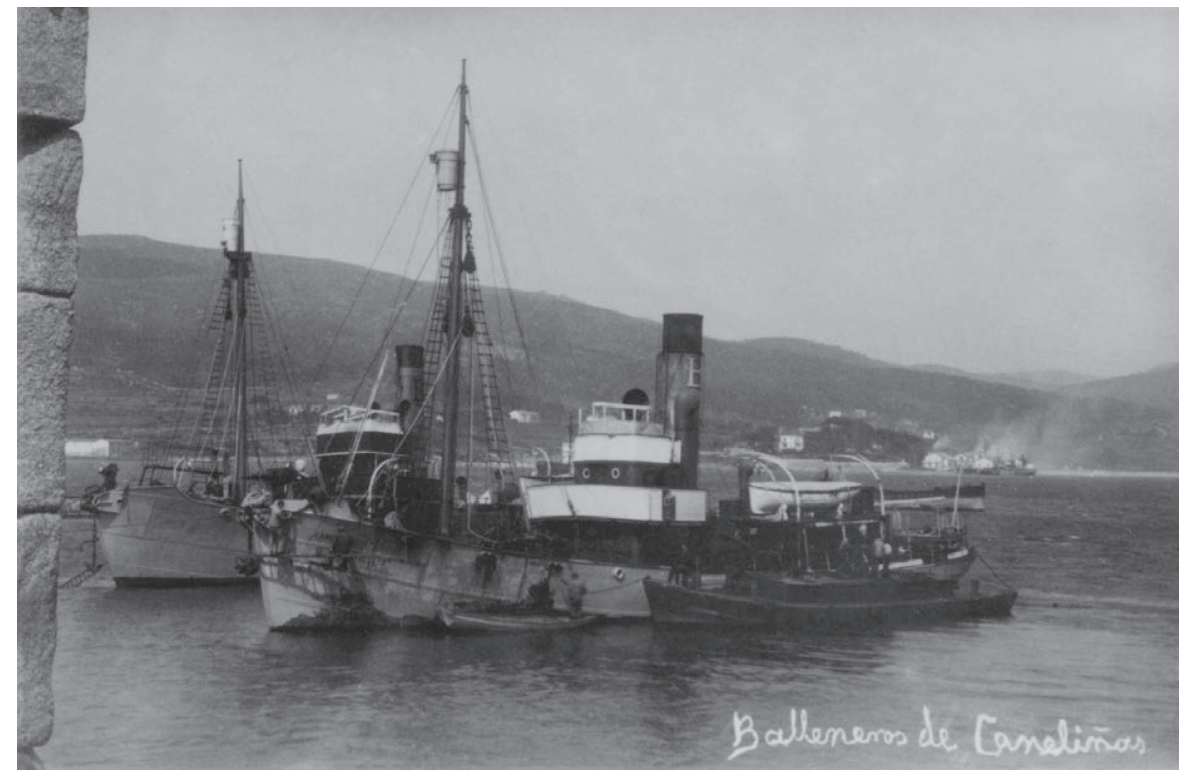

Fig. 2. Balleneros de la CBE amarrados en Corcubión (Museo de Pontevedra). 


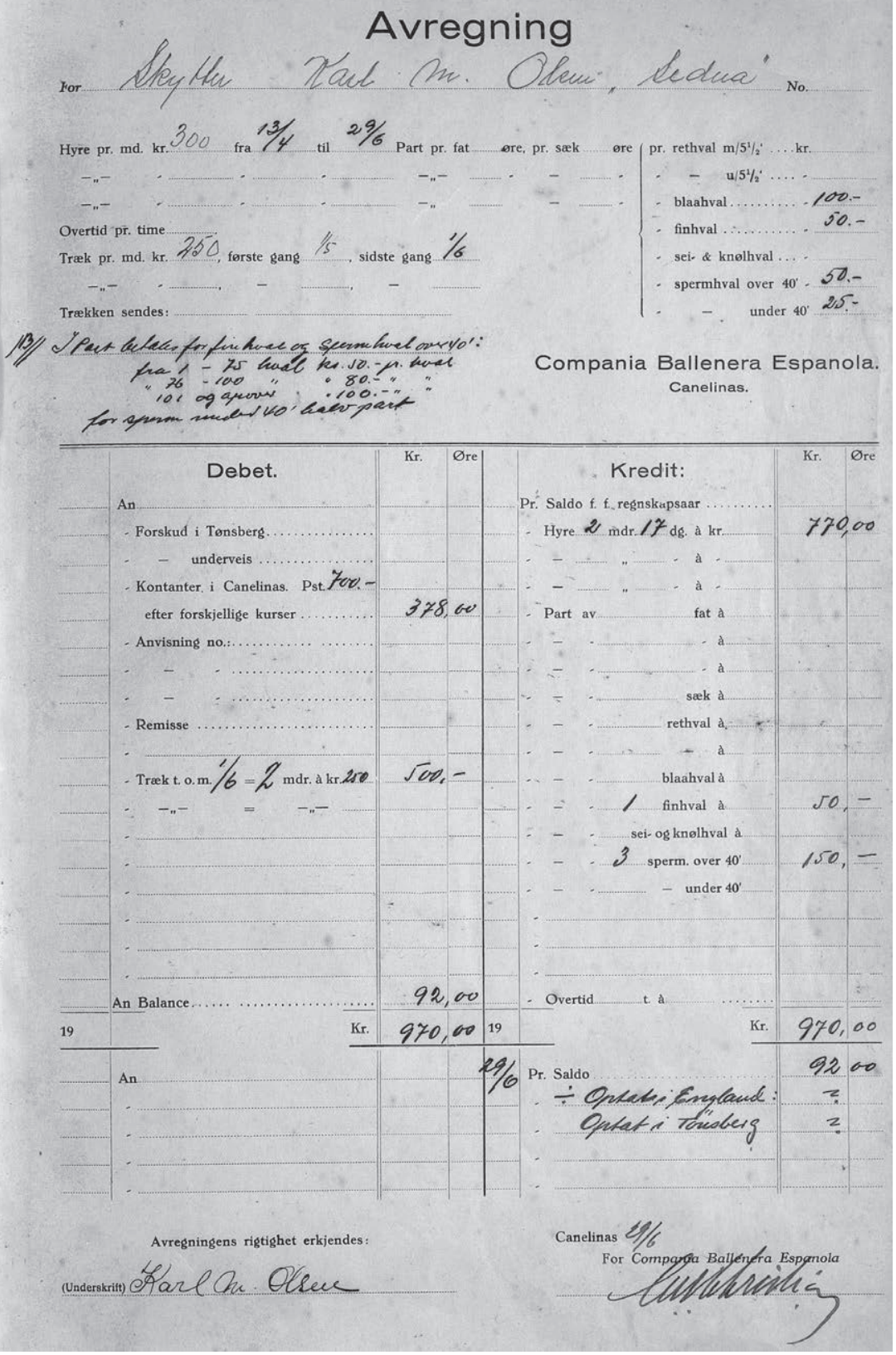

Fig. 3. Salario y primas de Karl M. Olsen, arponero del Sedna.

Libro de salarios de la CBE, año 1929, fol. 37 (foto de F. Valdés Hansen). 


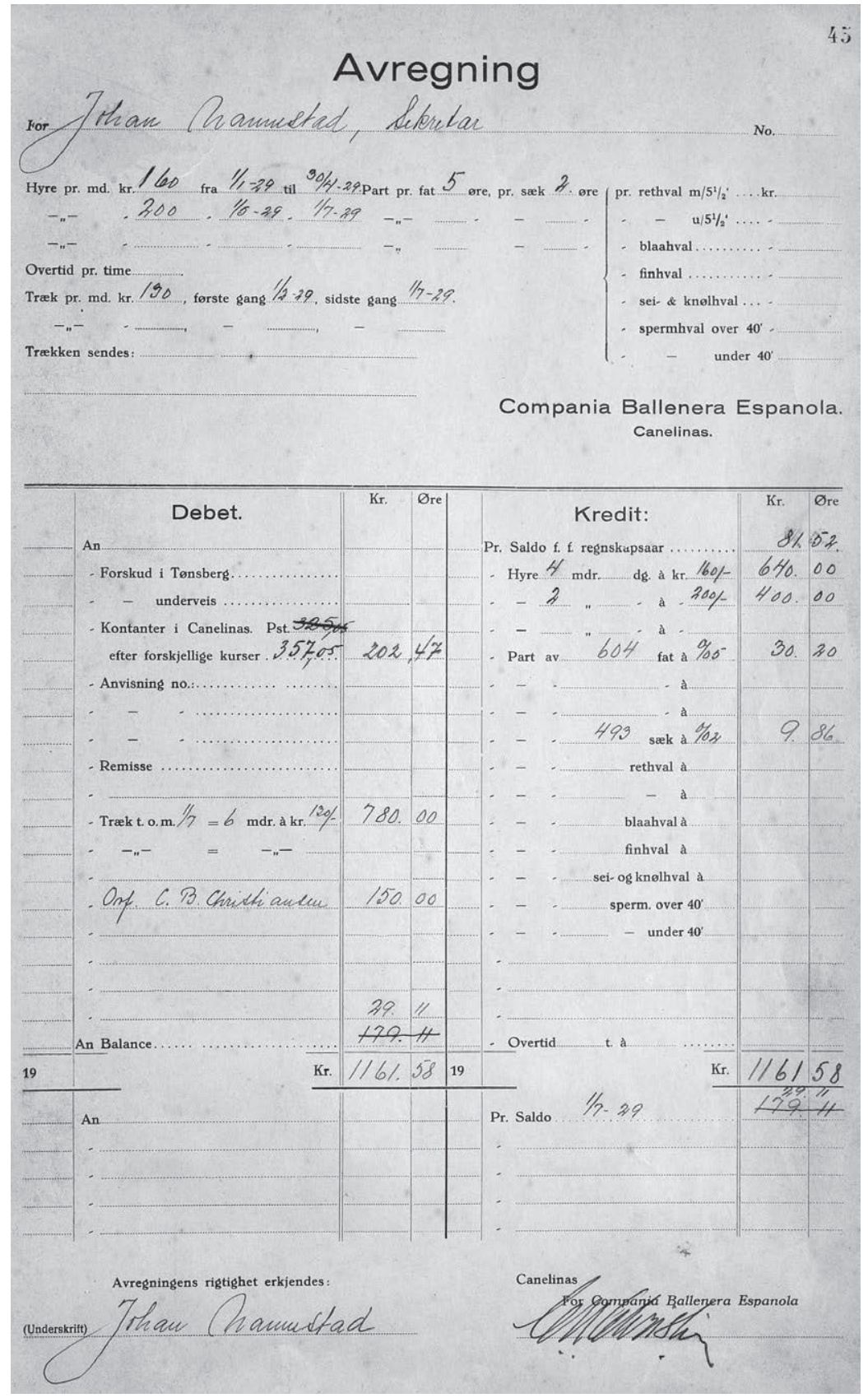

Fig. 4. Salario y primas del secretario Johan Nannestad.

Libro de salarios de la CBE, año 1929, fol. 45 (foto de F. Valdés Hansen). 


\section{BIBLIOGRAFÍA}

Aguilar, Àlex, Chimán, Barcelona, Universidad de Barcelona, 2013.

Anónimo: "Whaler ashore in Labrador", Evening Telegram, 01/09/1928, pág. 1.

Bernárdez, Ángel, "La pesca en Galicia”, en F. Carreras Candi (ed.), Geografia General del Reino de Galicia, vol. 1, Barcelona, Editorial Alberto Martín, 1936, págs. 517-553.

Cabrera, Ángel, "Los grandes cetáceos del estrecho de Gibraltar, su pesca y explotación", Trabajos del Museo Nacional de Ciencias Naturales, 52 (1925).

Compañía Ballenera Española (ed.), Memoria correspondiente al ejercicio del $1^{\circ}$ de enero al 31 de diciembre de 1925, Compañía Ballenera Española, Madrid, Pérez y Coca, 1926.

Dickinson, Anthony B. y Sanger, Chesley W., Twentieth-century shore-station whaling in Newfoundland and Labrador, Montreal, McGill-Queen's University Press, 2005.

Fernández Flórez, Wenceslao, La conquista del horizonte, Zaragoza, Librería General, 1942.

Gaceta de Madrid, Madrid, n 201 (20/07/1921).

Lardex Group [en línea], disponible en <http:/www.lardex.net/> [Consulta: 23/02/2014].

Lastres Carrera, Alejandro, "En la factoría de Caneliñas: Medio millón de pesetas en ámbar", La Voz de Galicia, 04/02/1925, pág. 1.

Penas Patiño, Xosé y Piñeiro Seage, Antonio, Cetáceos, focas e tartarugas mariñas das costas ibéricas, Santiago de Compostela, Dirección Xeral de Formación e Promoción Social Pesqueira, 1989.

Quiroga, Héctor, La caza de ballenas en aguas ibéricas, A Coruña, Diputación de A Coruña, 2002.

Skipshistorie [en línea], disponible en $<$ http://www.skipshistorie.net/> [Consulta: 04/05/2014].

Tønnessen, Johan Nicolay y Johnsen, Arne Odd, The history of modern whaling, Berkeley y Los Ángeles, University of California Press, 1982.

Valdés Hansen, Felipe, Los balleneros en Galicia (siglos XIII al XX), A Coruña, Fundación Pedro Barrié de la Maza, 2010 (Colección Galicia Histórica).

Valdés Hansen, Felipe, “A factoría baleeira de Balea (Cangas)”, Eubalanea, 14 (2014), págs. 41-56. 